\title{
Study on Ultimate Seismic Behavior and Repair Method of Damaged Steel Frames
}

Ayumu Ushigome*, Takumi Ito, Kenjiro Mori and Tomoe Onoda

Department of Architecture, Tokyo University of Science, Tokyo, Japan

\begin{abstract}
Recently, there are many discussions about repairability and recovery on damaged buildings. It is desirable to establish the design manuals for recovery considering continuous use of structures.

In our previous researches, the damaged steel members of $\mathrm{H}$-shaped and square tube section were reproduced by loading test. From the loading test results, the inelastic behavior and restoring force characteristics were clarified, and also the analytical model were proposed which can chase test results well. It means that we have already conducted the member based research on repairability.

So, in this study, to investigate the inelastic behavior and restoring force characteristics of repaired steel frames, the loading test is performed on half size scaled - partial frame model as parameters with strength ratio of column-beam and panel-beam. It is assumed that the various type of failure mode is generated on original state and repaired state. During loading test on original state, local buckling is observed on $\mathrm{H}$-shaped steel beam. Therefore, the damaged area is repaired by welding cover plates method which is recommended by Japanese restoration manual for damaged building structure by severe seismic disasters. And also, the loading tests on repaired state is performed, and it is confirmed that the strength is restored at the same or high level compared with original state. However, in case of beam failure mode on original state, different failure mode is observed on repaired state. Furthermore, a finite element analysis is performed, and the resistant mechanism during ultimate state is investigated analytically in detail.
\end{abstract}

Keywords: Steel frame; Repairability; Repair method; Strength ratio; Ultimate state; Partial frame

\section{Introduction}

Recently, there are many discussions about repair ability [1] and recovery on damaged buildings after severe disasters in Japan. And from these trends, a new keyword such as "Resilience" is noticed, which means revival potential or functional maintenance of damaged structure $[2,3]$. Furthermore, in recent years, there are global environmental and resources problems. Considering these problems, the establishment of design method and maintenance technique considering the concept of resilience and repair ability becomes increasingly important.

As an example of repair method for damaged steel members, authors focuses on repair method for plastic hinge or local buckling of the damaged steel members, such as $\mathrm{H}$-shaped (Especially, herein after referred to as "Box-shaped repair method") and square tube section, which have been suggested by a Japanese technical guideline for repairing damaged buildings [1,4] (herein after referred to as "the Japanese restoration manual") (Figure 1). From the loading test results, the inelastic behavior and restoring force characteristics of repaired steel members were clarified, and also the analytical model were proposed which can chase test results well [5]. Also, from the above studies, an analysis model of the repaired steel frame has been proposed. In the literature [6], analytical study was conducted on the ultimate limit state of repaired frame model, and the influences on the failure mode were investigated. From the remarkable conclusions of these previous studies, this research aims to clarify the restoring force characteristics and the load-carrying mechanism of repaired steel frame, and establishes a method for planning the performance evaluation and the suitable repair plan. This paper describes the result of loading test and the analytical study on finite element method.

\section{Outlines of Experimental Study}

\section{Test specimens and parameters}

To investigate the ultimate state and predominant failure mode on repaired steel frame, the test specimen is designed as a half size scaled partial steel frame.

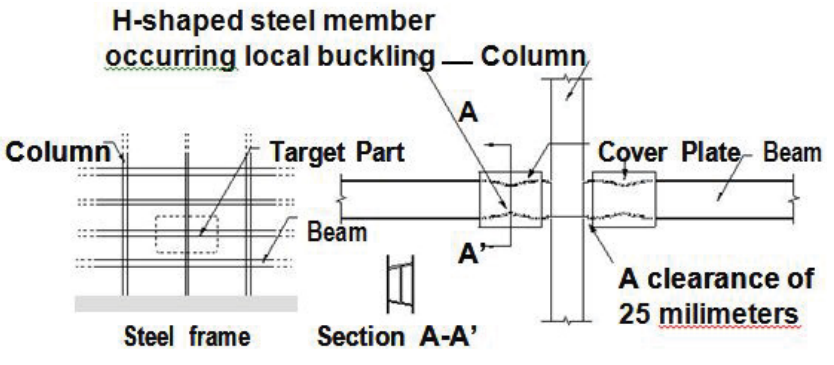

Figure 1: Target part and conceptual image of repairing method.

The column to beam connection is through - diaphragm type. The beam flange with non-scallop is welded the diaphragm by full penetration.

Herein, in case of repaired steel frame, the rigidity and strength around repaired portion is strengthened, so it is predicted that the distribution of strength and rigidity during frame has been changed. So it may be concerned that the failure mode of repaired frame is translated to different mode. Therefore, the strength ratio (column-beam, panelbeam) is considered as test parameters which occurs the different failure mode. Table 1 summarizes the list of test specimens, and Table 2 summarizes the mechanical properties of steel material.

*Corresponding author: Ayumu Ushigome, Department of Architecture, Tokyo University of Science, Shinjuku, Kagurazaka, 162-0825 Tokyo, Japan, Tel: +81 3-32604271; E-mail: a.ushigome0702@gmail.com

Received August 21, 2017; Accepted September 27, 2017; Published October 03, 2017

Citation: Ushigome A, Ito T, Mori K, Onoda T (2017) Study on Ultimate Seismic Behavior and Repair Method of Damaged Steel Frames. J Civil Environ Eng 7: 282 doi: 10.4172/2165-784X.1000282

Copyright: ( 2017 Ushigome A, et al. This is an open-access article distributed under the terms of the Creative Commons Attribution License, which permits unrestricted use, distribution, and reproduction in any medium, provided the original author and source are credited. 
Citation: Ushigome A, Ito T, Mori K, Onoda T (2017) Study on Ultimate Seismic Behavior and Repair Method of Damaged Steel Frames. J Civil Environ Eng 7: 282. doi: 10.4172/2165-784X.1000282

Page 2 of 5

\begin{tabular}{|c|c|c|c|c|}
\hline Name & Steel grades and section & Column-beam Strength Ratio & Beam- panel Strength Ratio & Failure Mode \\
\hline \multirow{2}{*}{ BR6-C } & Column : $\Upsilon-150 \times 150 \times 6($ BCR295) & \multirow{2}{*}{1.25} & \multirow{2}{*}{0.71} & \multirow{2}{*}{ Panel } \\
\hline & Beam : BH-190 × $120 \times 6 \times 6(\mathrm{SN} 400 \mathrm{~B})$ & & & \\
\hline \multirow{2}{*}{ BR9-C } & Column : $\Upsilon-150 \times 150 \times 9$ (BCR295) & \multirow{2}{*}{1.77} & \multirow{2}{*}{1.04} & \multirow{2}{*}{ Beam } \\
\hline & Beam : BH-190 × $120 \times 6 \times 6(\mathrm{SN} 400 \mathrm{~B})$ & & & \\
\hline
\end{tabular}

Table 1: List of test specimens.

\begin{tabular}{|c|c|c|c|c|}
\hline & Yield strength $\sigma y\left(\mathrm{~N} / \mathrm{mm}^{2}\right)$ & Tensile strength $\sigma \mathrm{u}\left(\mathrm{N} / \mathrm{mm}^{2}\right)$ & Elongation on (\%) & Young's Modulus (GPa) \\
\hline $\mathrm{SN} 400 \mathrm{~B}(\mathrm{t}=6 \mathrm{~mm})$ & 305 & 421 & 28.4 & 207 \\
\hline $\mathrm{SN} 400 \mathrm{~B}(\mathrm{t}=12 \mathrm{~mm})$ & 290 & 418 & 30.7 & 212 \\
\hline BCR295 (t=6 mm) & 419 & 482 & 18.8 & 219 \\
\hline BCR295 (t=9 mm) & 446 & 491 & 11.4 & 215 \\
\hline
\end{tabular}

Table 2: Mechanical properties of material.

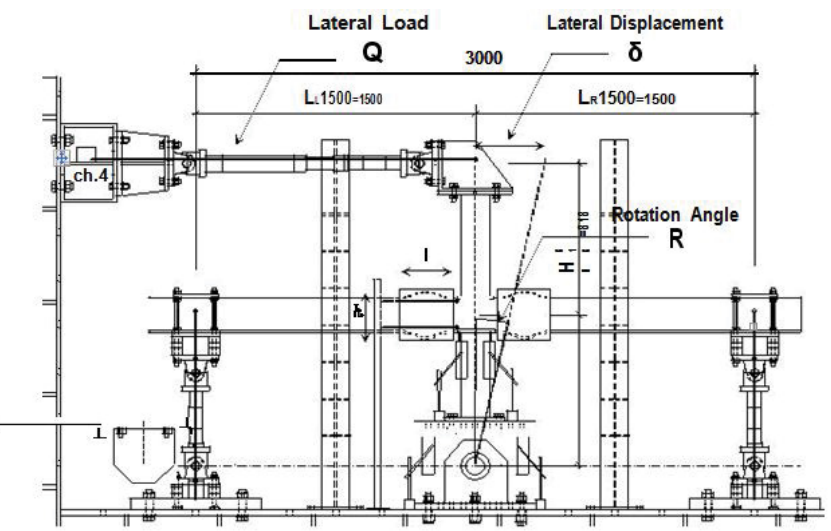

Figure 2: Elevation view of test specimen.

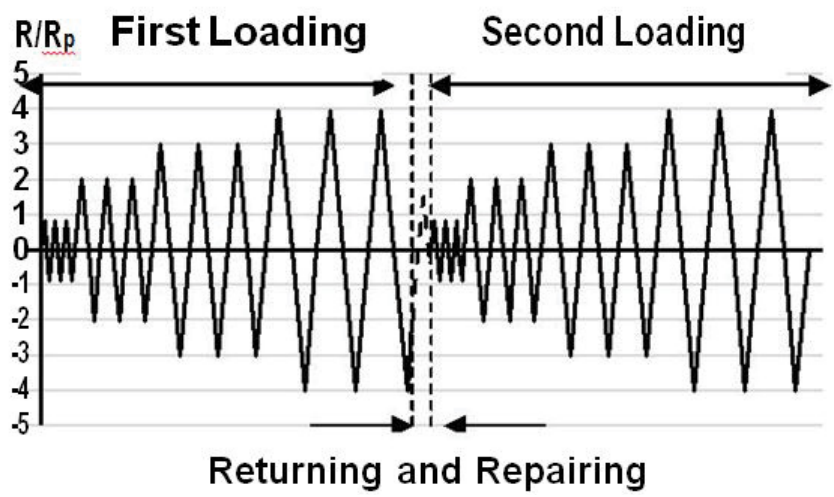

Figure 3: Loading program.'

\section{Test setup and measurement plan}

Figure 2 describes the elevation view of test specimens. The bottom of column is pin-supported, and the end of both side beams are pinrolar supported. The out-of-plane deformation is restrained by using jig at middle part of the beam. The top of column is laterally loaded by portable loading jack. Test specimens are instrumented with sensors for measuring below items: lateral load Q and lateral displacement $\delta$ at the top of the test specimens, deformation angle $\mathrm{R}$ is calculated by the below formula.

$$
\mathrm{R}=\delta /(\mathrm{HU}+\mathrm{HL})
$$

\section{Procedure of loading test and repair process}

At first, damaged state of test specimens are reproduced by loading tests which has residual deformation (herein after referred as "Original frame test specimen" and "First loading tests") on original test specimen (herein after referred as "original state"). Next, the damaged test specimens are returned to the original position (herein after referred as "Returning"). Then, the damaged portion is repaired by the Boxshaped repair method which has been suggested by the Japanese restoration manual. Finally, the loading tests are done on repaired test specimen (herein after referred as "repaired state"), which the same loading program is adopted as first loading tests (herein after referred as "Repaired frame test specimen" and "Second loading tests"). The evaluation and comparison with performance of the original states and repaired states are investigated.

The loading program is the increasing cyclic loading (Figure 3 ). The loading range is the elastic range $(0.85 \mathrm{Rp}), 2 \mathrm{Rp}, 3 \mathrm{Rp}, 4 \mathrm{Rp}$ every \pm 3 cycle, on the basis of the deformation angle $\mathrm{Rp}$ corresponding to the deformation angle $\mathrm{R}$, at which reaches the full plastic strength $\mathrm{Qp}^{*}$ at the first loading. Here, $\mathrm{Qp}^{*}$ is the laterally load $\mathrm{Q}$ corresponding to the minimum values of all full plastic strength cQp* (column), bQp*(beam), and $\mathrm{pQp}^{*}$ (panel).

$$
\begin{aligned}
& \mathrm{cQp}^{*}=\Sigma \mathrm{cMp}^{*} / \mathrm{HU} \\
& \mathrm{bQp}^{*}=\Sigma \mathrm{bMp}^{*} / \mathrm{HU} \\
& \mathrm{pQp}^{*}=\mathrm{pMp}^{*} / \mathrm{HU}
\end{aligned}
$$

Here, $\Sigma \mathrm{cMp}^{*}$ : Sum of column's full plastic moment.

$\Sigma$ bMp : Sum of beam's full plastic moment $\Sigma \mathrm{pMp}^{*}$ : Panel's full plastic moment HU: Span of upper column (Figure 2).

\section{Results of Test Study}

The normalized Q-R curves of loading tests are shown in Figures 4a and $4 \mathrm{~b}$. The lateral load $\mathrm{Q}$ is normalized by $\mathrm{Qp}{ }^{*}$, and the deformation angle $\mathrm{R}$ is normalized by $\mathrm{Rp}^{*}$.

\section{BR-6C test specimen}

On the first loading, the shear deformation is observed on the panel zone after reaching $\mathrm{Qp}^{*}$, and it progresses. Next, the local buckling is observed on the flange of left side beam at the compression side, and it progresses to the web of beam. From the observation of deformation of test specimen during first loading, the plastic deformation of panel zone is dominant; thus, it can be determined that the panel failure mode has been formed. Then, the loading is stopped because the local fracture of steel member is observed due to the weld defect at the connection between the flange of beams at tensile side and diaphragm. So the surface around fracture is smoothed with the grinder and welded again, and the loading is restarted. 
The shear deformation of the panel zone is observed, however, its excessive unstable deformation is not observed which occurs the strength deterioration by crack or fracture. On the other hand, the slight local buckling is observed around local buckling portion on the flange of beam, it causes the deterioration of strength earlier during second loading. Therefore, the panel zone is not repaired, however, the beam is only repaired by the Box-shaped repair method. The dimensions of the cover plate is determined as $180 \mathrm{~mm} \times 250 \mathrm{~mm}(\mathrm{l} \times \mathrm{h}$ at Figure 2$)$ by the waveform of local buckling. The cover plate is welded to the damaged area opened $20 \mathrm{~mm}$ from the column-beam connection.

On the second loading, the shear deformation is observed on the panel zone after reaching Qp* again. Then, the slight crack at the connection between panel zone and diaphragm and the shear buckling are observed, however, the deterioration of strength is not occurred. From the observation of deformation of test specimen during second loading, the plastic deformation of the panel zone is dominant; thus, it can be determined that the panel failure mode has been formed.

\section{BR9-C test specimen}

On the first loading, the local buckling is observed on the flange of beams at the compression side after reaching $\mathrm{Qp}^{*}$ and it progresses to the web of beam and reaches the maximum strength. From the observation of deformation of test specimen during first loading, the local buckling of beam is dominant; thus, it can be determined that the beam failure mode has been formed.

On the first loading, authors infer the strength deterioration due to the local buckling of beam. Therefore, the beam is repaired by the Box-

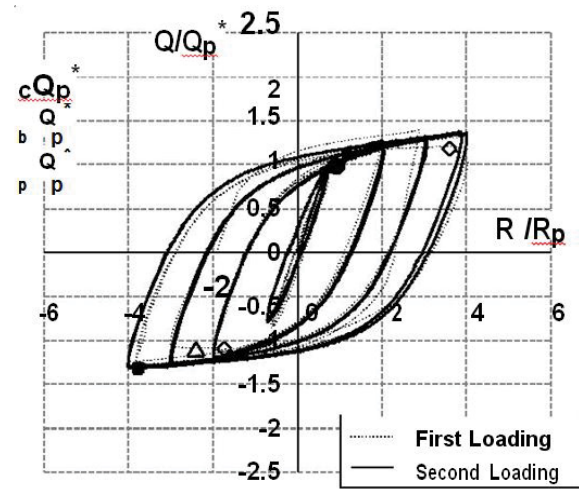

Figure 4a: Comparison of test result of normalized $Q-R$ hysteresis curve (BR6- C).

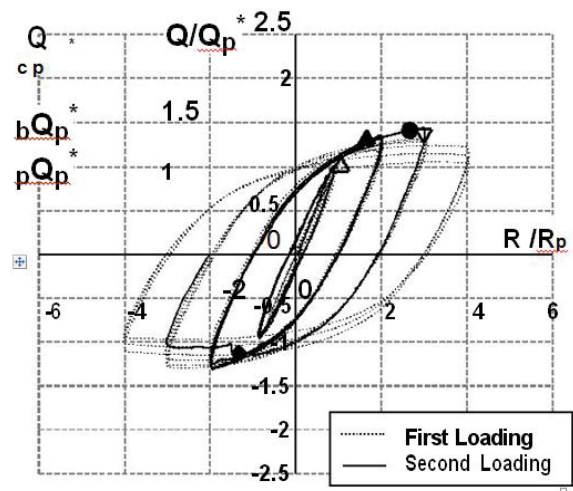

Figure 4b: Comparison of test result of normalized Q-R hysteresis curve (BR9- C).

\begin{tabular}{|c|c|c|c|c|c|c|}
\hline \multirow{3}{*}{ Name } & \multirow[t]{2}{*}{ Loading } & \multirow[t]{2}{*}{$\mathbf{T}$} & \multirow[t]{2}{*}{ cn } & \multicolumn{3}{|c|}{$\begin{array}{l}\text { Distribution diagram of } \\
\text { absorbed energy [\%] }\end{array}$} \\
\hline & & & & Column & Beam & Panel \\
\hline & \multicolumn{6}{|c|}{ First loading } \\
\hline \multirow{3}{*}{$\begin{array}{l}\text { Experimen- } \\
\text { tal Study }\end{array}$} & At the loading end & 1.31 & 69.4 & 2.5 & 80.7 & 16.8 \\
\hline & \multicolumn{6}{|c|}{ Second loading } \\
\hline & At the fracture & 1.44 & 19.9 & 1.7 & 31.1 & 67.3 \\
\hline & \multicolumn{6}{|c|}{ Repaired frame test specimen } \\
\hline \multirow{3}{*}{$\begin{array}{l}\text { Analytical } \\
\text { Study }\end{array}$} & At the fracture & 1.49 & 32 & 8.2 & 41.1 & 50.7 \\
\hline & \multicolumn{6}{|c|}{ Non-repaired frame test specimen } \\
\hline & At the loading end & 1.14 & 76.8 & 0.1 & 99.6 & 0.3 \\
\hline
\end{tabular}

Table 3: Comparison of test result of original state and repaired state.

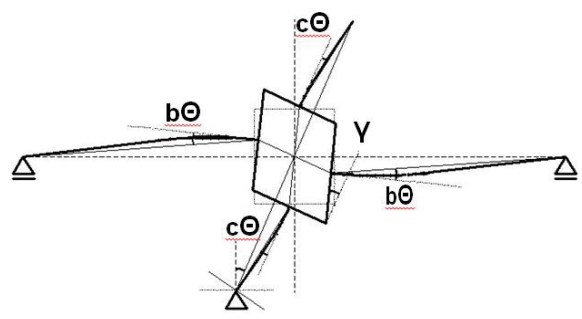

Figure 5: Deformation angle of each member.

shaped repair method. The dimensions of the cover plate is determined as $280 \mathrm{~mm} \times 270 \mathrm{~mm}(1 \times \mathrm{h}$ at Figure 2$)$ by the waveform of local buckling. The cover plate is welded to the damaged area opened $20 \mathrm{~mm}$ from the column-beam connection.

On the second loading, the new local buckling is observed on the flange of beams at outer cover plate at the compression side after reaching over $\mathrm{Qp}^{*}$. Next, the shear deformation is observed on the panel zone, and it progresses. Eventually, the loading is ended because the fracture is observed at the welding connection between the flange of right side beam at the tensile side and the diaphragm. From the observation of deformation of test specimen during second loading, the shear deformation of the panel zone is dominant; thus, it can be determined that the panel failure mode has been formed. From the test result, the beam failure mode has been formed on the original state, however, the failure mode of the repaired state is translated to panel failure mode by repairing beams.

\section{Examination of Test Results}

\section{Verification of repair effect}

Table 3 compares the test results at the original state and repaired state. $\tau$ is the standardized strength increasing rate $\left(\mathrm{Qm}^{*} / \mathrm{Qp}^{*}\right)$. Herein, $\mathrm{Qm}^{*}$ is the maximum strength. $\mathrm{c} \eta$ is the energy absorption capacity, and the ratio of original state and repaired state.

Table 3 shows the distribution diagram of absorbed energy of each member. Here, the deformation angle of each member related with the absorbed energy is calculated based on Figure 5.

\section{BR6-C test specimen}

From the comparison of Table 3, $\tau$ and $\mathrm{c}$ shows similar value of original state and repaired state. It is assumed that the panel failure mode is formed and the unstable behavior of panel zone is not occurred during the first and second loading.

And also, from the results of Table 3, it is confirmed that the local buckling occurs on the beam during first loading, however, its deformation doesn't progress during second loading. From this 
observation, the deformation of panel zone is dominant during second loading.

\section{BR9-C test specimen}

From the comparison of Table 3, $\tau$ and $\mathrm{cn}$ of second loading are improved by comparison with the results of first loading. It is assumed that the strength of the beam is improved by repairing beams. On the other hand, through the entire range of the loading program, $\mathrm{c} n$ is deteriorated compared with the result of first loading. It is assumed that the beam end reaches the nearly maximum strength, and the fracture occurs at the welding connection between the flange of beam on the tensile side and diaphragm during second loading.

And also, from the result of Table 3, it is confirmed that the deformation of beam in the repaired frame test specimen is restrained, and the damage is concentrated on the panel zone during the second loading. it is assumed that the strength of beam is improved by repairing beams.

\section{Influence of Repairing}

\section{BR6-C test specimen}

In BR6-C test specimen, authors execute a repair plan adopting on damaged beam with local buckling occurrence, and the panel failure mode is formed even in the repaired frame test specimen. From the result, it is confirmed that the strength and the energy absorbed capacity present almost same as the original state.

On the other hand, the damaged test specimen with crack around connection is confirmed. It is possible that it attributes to cause the unstable behavior after second loading. Therefore, it is desirable that the correct repairing plan should be structured which prevents from concentrated yielding and plastic progressive deformation.

\section{BR9-C test specimen}

In BR9-C test specimen, authors also execute a repair plan adopting on damaged beam with local buckling occurrence which causes the deterioration of strength. From the result, it is confirmed that the strength is improved by repairing beams, and the failure mode of the repaired state is translated to panel failure mode. In addition, the end of repaired beams reaches the maximum strength and the fracture occurs at the welding connection between the flange of beam at the tensile side and diaphragm. Therefore, it is desirable that the correct repairing plan should be structured which prevents from translation of the failure mode.

From the comparison of test result of each specimens, the different ultimate state is observed between the first and second loading. It is assumed that the repairing beams by the Box-shaped repair method causes to change the distribution of strength and rigidity during frame. From the above, it is important to execute the suitable repair plan considering to change the distribution of the strength, the rigidity, and the failure mode.

\section{Examination of Finite Element Method}

To simulate the restoring force characteristics and inelastic behavior on non-repaired steel frame which formed the plastic failure mechanism, a finite element method (FEM) analysis is performed on BR9-C test specimen. The software "MSC Marc-2013" as the general non-linear finite element method analysis program is adopted on FEM analysis in this paper. The analysis model is assumed by reference of the experimental test specimens. The analytical model is illustrated in Figure 6. It has the initial imperfection related to deformation of local buckling to reproduce the damage by first loading during experimental
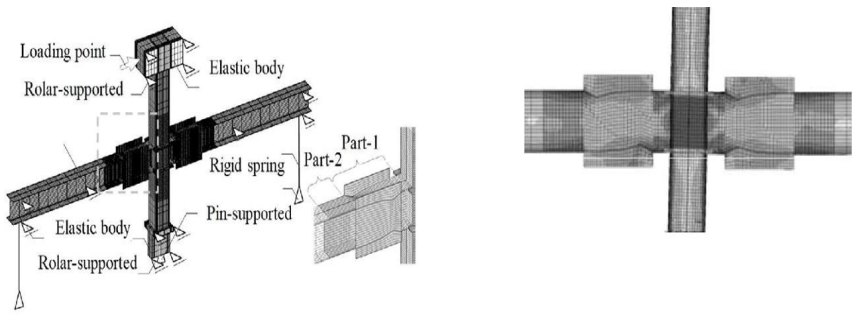

Figure 6: FEM analytical model.

\begin{tabular}{|c|c|c|c|c|c|c|}
\hline \multirow{3}{*}{ Name } & \multirow[t]{2}{*}{ Loading } & \multirow[t]{2}{*}{$\mathbf{T}$} & \multirow[t]{2}{*}{ cn } & \multicolumn{3}{|c|}{$\begin{array}{l}\text { Distribution diagram of ab- } \\
\text { sorbed energy [\%] }\end{array}$} \\
\hline & & & & Column & Beam & Panel \\
\hline & \multicolumn{6}{|c|}{ First loading } \\
\hline \multirow{4}{*}{$\begin{array}{l}\text { Experi- } \\
\text { mental } \\
\text { Study }\end{array}$} & At the loading end & 1.31 & 69.4 & 2.5 & 80.7 & 16.8 \\
\hline & \multicolumn{6}{|c|}{ Second loading } \\
\hline & At the fracture & 1.44 & 19.9 & 1.7 & 31.1 & 67.3 \\
\hline & \multicolumn{6}{|c|}{ Repaired frame test specimen } \\
\hline \multirow{3}{*}{$\begin{array}{l}\text { Analytical } \\
\text { Study }\end{array}$} & At the fracture & 1.49 & 32 & 8.2 & 41.1 & 50.7 \\
\hline & \multicolumn{6}{|c|}{ Non-repaired frame test specimen } \\
\hline & At the loading end & 1.14 & 76.8 & 0.1 & 99.6 & 0.3 \\
\hline
\end{tabular}

Table 4: Comparison of experimental and analytical result.

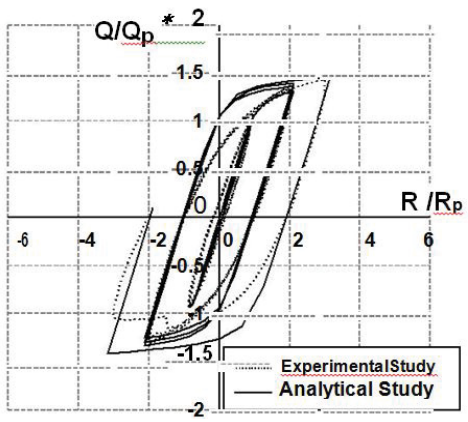

Figure 7a: Analytical result of repaired frame ( $Q-R$ curve)

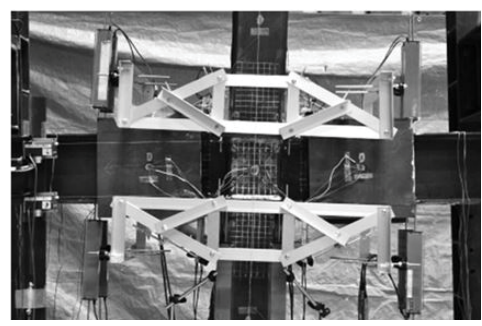

Figure 7b: Analytical result of repaired frame (ultimate state)

study. In case of original state, the material properties of analysis model obtained from material test results are adopted. And in case of repaired state, the material properties of damaged parts such as local buckling and plastic hinge are assumed the inelastic characteristics [7-9].

\section{Analysis Results and Consideration}

Table 4 compares the test results and FEM analysis results on original state and repaired state respectively. Figures $7 \mathrm{a}$ and $7 \mathrm{~b}$ compares the ultimate state of test results and FEM analysis too. Figures $8 \mathrm{a}$ and $8 \mathrm{~b}$ shows the hysteresis loop of FEM analysis on repaired state and nonrepaired state. 


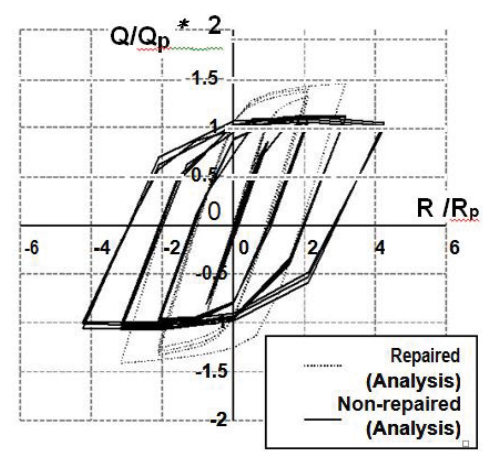

Figure 8a: Analytical result of the non-repaired frame ( $Q-R$ curve)

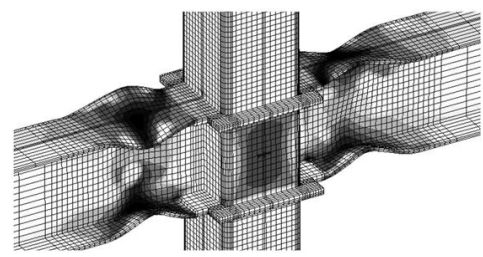

Figure 8b: Analytical result of the non-repaired frame (ultimate state).

From the results of Figures 7a and 7b, FEM analysis shows good agreement with the test result. And from the results of Table 4, it is considered that the failure mode and the ultimate state can be reproduced because the distribution diagram of absorbed energy of panel zone becomes large, and it show the same trend with test result.

From the results of Figures $8 \mathrm{a}$ and $8 \mathrm{~b}$, result of FEM analysis shows that the maximum strength of non-repaired state is smaller than repaired state. From the result of Table 4, result of FEM analysis shows that the maximum strength of non-repaired state is smaller than repaired states. And the distribution diagram of absorbed energy of beam is by far the largest of all members at non-repaired state. It is also confirmed that the damage concentrates on the damaged part of beam again. Therefore, it is assumed that the strength is deteriorated by the local buckling progressing.

\section{Conclusion}

In this study, the experimental and analytical study about recovery of steel members in the frame is performed. The main conclusions are shown below:

1. In the panel failure mode type test specimen (BR6-C), it is confirmed that the failure mode after repair is not translated to the panel during second loading. However, the distribution of the strength changed by improving the strength of beams by repairing.

2. In the beam failure mode type test specimen (BR9-C), it is confirmed that the failure mode after repair is translated to the panel by improving the strength of the beams by repairing.

3. When repairing the damaged frame, it is important that the correct repairing plan should be structured which considering to change the distribution of the strength, the rigidity, and the failure mode.

4. On the non-repaired state at FEM analysis, it is confirmed that the damage concentrates on the damaged part again. Therefore, the damaged part should be properly repaired.

\section{Acknowledgement}

The experiment of this research was subsidized by the Grant for Scientific Research grant project in 2016 (Grant-in-Aid for Scientific Research Grant) · Basic Research (B) (Research Representative: Koji Uetani). In addition, this experiment was conducted at the Katsura INTEC Center attached to the Graduate School of Engineering, Kyoto University.

We received valuable guidance and great cooperation from Kyoto University Professor Yoshikazu Araki, Yuji Koetaka, Nobutoshi Yoshida, Masahiro Nomura. In addition, we got valuable advice and guidance from Okuda Corporation in repair. Thank you for writing here.

\section{References}

1. No authors listed (2000) The Concept of Performance-based Structural Design Method in Building Structure - Performance from Specifications (in Japanese) Gihodo Publishing.

2. No authors listed (2011) Japanese Architectural Institute: Structural Design of Building with Improved Robustness and Redundancy, Structural Division of Japanese Architectural Institute.

3. AlJ (2012) Japanese Architectural Institute: 1st Anniversary Resilient Society of the East Japan Earthquake. Architectural Magazine.

4. Yoshiaki N, Masaki M, Hiroshi K, Masaya M (2015) Guideline for post earthquake damage evaluation and rehabilitation technique revised edition (in Japanese). The Japan Building Disaster Prevention Association.

5. Mori K, Ito T, Sato H, Munemura H, Matsumoto T, et al. (2015) Repairability performance and restoring force characteristics of damaged $\mathrm{H}$-shaped stee members after repair. International Joumal of High-Rise Buildings 4: 57-64.

6. Mori K, Ito T, Munemura H, Fuse H (2015) A study on ultimate seismic limit state after repair of plastic failured steel frame.

7. Mori K, Ito T, Munemura H, Fuse H (2015) A study on the ultimate seismic limit state after the repair of plastic collapse steel frame (Part 1) (Part 3). The Architectural Institute of Japan, Academic Lecture Collection Summary.

8. Mori H, Ito T, Mori K, Munemura H, Fuse H, et al. (2015) Repairability and recovery of structural performance of damaged steel members with buckling and fractures. The Journal of the Japanese Institute of Architectural Studies.

9. (2001) Recommendation for design of connection in steel structures. 